\title{
Saúde bucal: uma revisão crítica sobre programações educativas para escolares
}

\author{
Oral health: a critical review about educative \\ programmes for students
}

Adriana Regina Colombo Pauleto 1

Maria Lucia Toralles Pereira 2

Eliana Goldfarb Cyrino 3

\footnotetext{
1 Programa de Pós-Graduação em Saúde Coletiva, Faculdade de Medicina de Botucatu, Universidade Estadual Paulista. Rua Sérvio Túlio Carrijo Coube 3-33/31, bloco A, Jd. Infante Dom Henrique, 17044-490, Bauru SP.

adrianapauleto@hotmail.com

2 Departamento de Educação. Programa de Pós-Graduação em Saúde Coletiva, Faculdade de Medicina de Botucatu, Universidade Estadual Paulista.

3 Departamento de Saúde Pública. Faculdade de Medicina de Botucatu, Universidade Estadual Paulista.
}

Abstract The Brazilian epidemiological situation in oral health is still serious due to inappropriate social and economic conditions of the population; the small amount of investment compared to the total amount of SUS; and lack of information about basic health cares. Although the dentistry sector seems to be very developed regarding technology, it does not meet significantly the population demand for oral health. In accordance to this fact, oral health education has been required every day more, with regard to the low costs and the possibilities of odontologycal impact on public and collective scope. The main reason for this study was the importance of preventive and educative actions in oral health, aiming different odontologycal programmes by means of review studies, to analyse their proposals, methodologies, possibilities and limitations, seeking to consider the theme focusing in educative aspects that still challenge oral health programmes. In the analysed programmes were identified four tendencies. The study pointed out the necessity of rethink the educative actions.

Key words Educative programmes, Oral health, Health programmes, Education in health
Resumo Em saúde bucal, a situação epidemiológica brasileira ainda é grave devido às condições sociais e econômicas da população, à pequena parcela de investimentos que a área recebe em relação ao total do SUS e à falta de informação sobre os cuidados básicos de saúde. Embora a odontologia se mostre muito desenvolvida em tecnologia, não responde em níveis significativos às demandas dos problemas de saúde bucal da população. Nesse contexto, a educação em saúde bucal tem sido cada vez mais requisitada, considerando o baixo custo e as possibilidades de impacto odontológico no âmbito público e coletivo. A importância de práticas preventivas e educativas em saúde bucal nos levou a realizar este estudo, apontando diferentes programas odontológicos, mediante estudo de revisão, para analisá-los em suas propostas, metodologias, possibilidades e limitações, visando refletir sobre o tema com foco nos aspectos educativos que ainda desafiam os programas de saúde bucal. Identificaram-se quatro tendências nos programas analisados. O estudo apontou para a necessidade de se repensar as práticas educativas.

Palavras-chave Programas educativos, Saúde bucal, Programas em saúde, Educação em saúde 


\section{Introdução}

A cárie dentária e a doença periodontal são os males que mais acometem a cavidade bucal, sendo a cárie o mais comum em crianças. Thyslstrup e Fejerskov (1995) descrevem a cárie como um processo dinâmico que ocorre nos depósitos bacterianos (placa bacteriana na superfície dos dentes), resultando em uma alteração do equilíbrio entre a superfície dentária e o fluido da placa que, com o passar do tempo, leva à perda mineral.

No Brasil, a prevalência da cárie dentária medida aos 12 anos de idade vem diminuindo desde a década de 1970, apesar de já ter sido um dos maiores CPO-D do mundo (representa a média de dentes cariados/C, dentes perdidos/ $\mathrm{P}$ e dentes obturados/O) (OPAS/OMS, 2001).

Conforme o levantamento epidemiológico nacional de 1986, realizado na zona urbana em 16 cidades, a pior situação aparecia entre as pessoas de menor renda. Para o grupo da faixa etária de 6-9 anos, o índice CPO-D encontrado obteve a média de 2,68 dentes cariados, e para o grupo etário de 10-12 anos, 5,56 dentes cariados (Brasil, 1989). Em 1996, dez anos depois desse levantamento, outro estudo realizado pelo Ministério da Saúde nas capitais brasileiras, pesquisando somente a cárie dental entre escolares de 6 a 12 anos, mostrou uma redução de 53,9\% na população estudada, atingindo praticamente os parâmetros da Organização Mundial de Saúde (OMS) para o ano 2000, que é de um índice CPO-D menor ou igual a 3,0 (Brasil, 1999).

Essa queda não é uniforme nem homogênea pelo vasto território brasileiro. Pode-se considerar que varia, dentre outros fatores, segundo as características de abastecimento de água de cada região, dos sistemas locais de saúde e das classes sociais e seus diferenciais de consumo. Em regiões com água fluorada e cujos teores são mantidos adequados, a redução pode ser atribuída a essa medida (Frazão, 2000).

A fluoração das águas de abastecimento público foi aplicada pela primeira vez no Brasil em 1953 no município de Baixo Guandu, Espírito Santo. Constitui um meio coletivo importante para a prevenção da cárie dentária pelos resultados que produz: redução de aproximadamente 60\% na prevalência da doença depois de 10 anos de utilização (Frazão, 1998).

Em 1974, o Congresso Nacional aprovou a lei federal n. 6.050, que determina a obrigatoriedade da fluoração dos municípios com estações de tratamento de água. Diversas entidades e órgãos defendem que a fluoração das águas de abastecimento público é uma medida ideal de saúde pública para a prevenção da cárie dentária, devido à sua eficácia, segurança e, principalmente, ao baixo custo. Esta medida exige, no entanto, o controle dos níveis de flúor pela Vigilância da Qualidade da Água para o Consumo Humano, realizado pelos serviços de saúde (Frazão 1998).

A saúde bucal, implícita na saúde integral, está relacionada às condições socioeconômicas e culturais da população. Como observa Porto (2002), a saúde bucal está diretamente relacionada às condições de alimentação, moradia, trabalho, renda, meio ambiente, transporte, lazer, liberdade, acesso a serviços de saúde e informação. Nesse sentido, a luta pela saúde bucal está, fundamentalmente, ligada à luta pela melhoria dos determinantes sociais, políticos e econômicos.

A educação e a informação sobre os cuidados com a saúde bucal têm sido ressaltadas por diversos pesquisadores. O desconhecimento sobre cuidados necessários de higiene bucal representa um fator a ser considerado, uma vez que a informação, embora disponível nas grandes mídias, não chega a todas as camadas da população da mesma forma e, dificilmente, é apreendida de modo a produzir conhecimento e autonomia em relação aos cuidados com a saúde. A importância de programas odontológicos educativos, que levantem e interpretem as necessidades das populações de menor acesso aos serviços de saúde odontológicos precisa ser valorizada.

\section{Política Nacional de Saúde Bucal}

Botazzo (1994) observa que, até a década de 1970, a maioria das ações coletivas, no campo da saúde bucal, era descontínua e esporádica, sendo executada na semana dos bons dentes ou algo parecido. Essas ações apresentavam mais características de campanha do que de programa. Em instituições de saúde mais bem estruturadas, procurava-se adotar como base de um único método de prevenção, por exemplo: ou a fluoração das águas de abastecimento público ou a realização de bochechos fluorados semanais.

As crises econômicas, os desajustes sociais e uma inadequação do sistema de atenção clínica e preventiva à população figuram entre as mais notórias razões que explicam os contrastes ob- 
servados na realidade brasileira, além do limitado acesso da população aos serviços disponíveis e do isolamento entre si das entidades que atuam nessa área (Brasil, 1989).

Procurando dar uma resposta correta a essa situação, a Divisão Nacional de Saúde Bucal, órgão da Secretaria Nacional e a Coordenadoria de Supervisão e auditoria de Odontologia do Inamps elaboraram, em 1989, a Política Nacional de Saúde Bucal. As prioridades dessa política são definidas segundo os grupos populacionais, tipos de serviços, danos, recursos humanos, modalidades de organização e financiamento do setor (Brasil, 1989).

O texto constitucional que formula o Sistema Único de Saúde (SUS), sua regulamentação, e outros textos normativos constituem as bases legais para as ações de saúde bucal no SUS, propondo seguir os mesmos princípios que regem a dimensão macro da saúde, ou seja, um direito básico acessível a todos os cidadãos, pautado na universalidade, na eqüidade, na integralidade, compondo um sistema descentralizado, hierarquizado em diferentes niveis de complexidade, e que esteja regulado através do controle social (Silveira Filho).

Conforme apontam Barros e Bertoldi (2002), dados da Pesquisa Nacional por Amostragem de Domicílios (PNAD), de 1998, realizada pelo IBGE, revelam que a saúde bucal no Brasil tem recebido uma parcela escassa de recursos em relação ao total de investimentos do SUS. Do ponto de vista do acesso aos serviços odontológicos, o SUS é um agente de grande importância, porém com um papel proporcionalmente pequeno: em 1998, revela a pesquisa, apenas $5,24 \%$ dos investimentos em saúde se destinavam aos procedimentos odontológicos.

As políticas de saúde bucal do SUS buscam favorecer a transformação da prática odontológica por meio da incorporação de pessoal auxiliar, novas tecnologias e ações coletivas de saúde, visando alterar suas características epidemiológicas e obter impacto na cobertura da população e na construção da cidadania. Para atingir essas metas, é imprescindível criar e incentivar práticas comunitárias que possibilitem o crescimento da consciência sanitária e a mobilização da sociedade civil em torno das questões de saúde.

Apesar de as conquistas do movimento sanitário brasileiro terem sido consolidadas parcialmente na atual Constituição, na prática, essas conquistas não têm sido concretizadas em melhoria da qualidade de vida da população brasileira. No Brasil, um dos desafios que se co- loca para a prática profissional da odontologia (produção de conhecimento, produção de serviços e desenvolvimento de recursos humanos) está baseado no estabelecimento de uma atuação responsável na luta pela conquista dos objetivos que incluem a liberdade, os direitos e deveres individuais e coletivos, tendo em vista alcançar a máxima plenitude de qualidade de vida (Brasil, 1993).

Nas últimas décadas, foi grande o desenvolvimento de produção, distribuição e consumo de uma quantidade enorme de bens e serviços relativos à problemática da saúde bucal. Narvai (1994) admite que, aproximadamente, 3,4 bilhões de dólares por ano são movimentados, incluindo, entre outros aspectos, a formação e remuneração de recursos humanos odontológicos e o faturamento da indústria de materiais, de equipamentos e de produtos de higiene bucal. Analisando as propostas e as ações relativas à prática odontológica no Brasil no período de 1952-1992, o autor observou que estas se caracterizavam por uma odontologia de mercado, sob a influência político-ideológica do projeto de sociedade neoliberal, apoiada na assistência odontológica individual, realizada no restrito ambiente clínico cirúrgico.

Essa concepção exerce forte influência no desenvolvimento da ciência e da tecnologia em saúde bucal, mas não responde, de modo significativo, aos problemas de saúde bucal da população, porque se trata de uma prática de custo alto e baixa cobertura, com enfoque, essencialmente, curativo. Como observa Garrafa (1993), trata-se de uma odontologia tecnicamente elogiável (pelo nível de qualidade e sofisticação inegavelmente alcançado nas diversas especialidades), cientificamente discutível (uma vez que não tem demonstrado competência em expandir esta qualidade para a maioria da população) e socialmente caótica (pela inexistência de impacto social ante as iniciativas e programas públicos e coletivos implementados).

Dentro desse modelo, também Pinto (1992) observa que aproximadamente $2 / 3$ dos trabalhadores não têm no Brasil condições reais de serem atendidos em clínicas privadas, nas quais se concentram 3/4 do tempo de trabalho ofertado pelos cirurgiões-dentistas.

Contrapondo-se à odontologia de mercado, Narvai (1994) aponta que muitas propostas e ações foram e vêm sendo implementadas no Brasil com o propósito de impedir o predomínio dessa visão na organização da assistência odontológica e do sistema de atenção à saúde 
bucal. São propostas que visam à maior aproximação com os determinantes do processo saúde-doença bucal, considerando as políticas econômicas e sociais, especialmente as de saúde e educação, e manifestam explícita vinculação a projetos sociais em que a saúde tem relevância pública, com prioridade pelo Estado e pela sociedade. Referindo-se a esse movimento, Botazzo (1994) afirma: A saúde bucal coletiva deve direcionar-se para o social como o lugar de produção das doenças bucais e aí organizar tecnologias que visem não a "cura" do paciente naquela relação individual-biológica... mas sim a diminuição e o controle sobre os processos mórbidos tomados em sua dimensão coletiva.

Propostas com o foco no coletivo ainda representam um desafio ao campo da odontologia, tanto pelo fato de a formação na área dirigir-se para o individual, quanto pelo fato de apenas uma pequena parte do investimento feito em ciência e tecnologia dirigir-se aos problemas de saúde bucal com relevância para a saúde pública.

Nesse contexto, a educação em saúde, como prática social voltada para o coletivo, representa uma importante possibilidade de ampliar a atuação das práticas de promoção da saúde bucal no espaço público. Soares (1988) aponta que muitas medidas preventivas permitem combater a cárie e a doença periodontal. A higiene bucal, fluoração e alimentação não-cariogênica constituem medidas eficazes para fazer frente aos problemas bucais. Mas, para que tenham êxito, precisam fundamentar-se em programas educativos.

\section{Programas em saúde pública}

Uma política, designada Programação, foi a forma específica como a saúde pública de São Paulo se engajou nesse movimento, propondo a ampliação e diversificação da assistência médica na rede de centros de saúde, antes restrita a algumas doenças infecciosas e a atividades higienistas e preventivas como o pré-natal. A proposta da Programação buscou realizar essa ampliação de modo que a assistência médica fosse um dos meios do trabalho definido epidemiologicamente ( $\mathrm{Ne}$ mes et al. 1996).

As práticas programáticas constituem a forma de organizar o trabalho coletivo no serviço de assistência à saúde.

A ação programática em saúde pode ser definida como uma proposição de organizar o traba- lho em saúde fundamentada no ideal da integração sanitária, para o que busca inspirar-se em tecnologias de base epidemiológica. Esse é o ponto de partida lógico para a estruturação dos programas de saúde. Ainda segundo Nemes et al. (1996), a programação em saúde articula instrumentos de trabalho dirigidos a indivíduos, entre eles a assistência médica individual, a instrumentos diretamente dirigidos a coletivos, objetivando potencializar a efetividade epidemiológica de todos os instrumentos.

No caso específico da programação em saúde bucal, em nosso país, pode-se perceber a existência de diversas formulações, algumas voltadas a ações coletivas, outras mais centradas no atendimento clínico individual e muitas focadas na assistência à criança. Estudo realizado em Botucatu, por Cyrino (1994), aponta que muitas vezes essas programações em saúde bucal estão descoladas ou desarticuladas de uma programação maior voltada à populaçãoalvo, com ações educativas e preventivas.

A existência de programas odontológicos com diferentes abordagens, nem sempre claras quanto às concepções de saúde, de conhecimento e de práticas comunicacionais que utilizam, motivou realizar este estudo e analisar abordagens de programas desenvolvidos em saúde bucal no Brasil, nos últimos dez anos, para compreendê-los criticamente, em suas possibilidades e limitações.

\section{Objetivo}

O objetivo deste trabalho foi rever os principais programas educativos em saúde bucal, visando desenvolver uma reflexão crítica sobre o tema, tendo em vista contribuir para a elaboração de novos programas educativos na área de odontologia. Além disso, buscamos trazer para o espaço de discussão alguns aspectos pedagógicos que têm desafiado as práticas de educação em saúde: problematização do cuidado com a saúde bucal; aprendizagem significativa; construção de conhecimento emancipatório; autonomia em relação aos cuidados com a saúde; direito à informação e cidadania.

\section{Metodologia}

Trata-se de uma revisão bibliográfica sobre programas em saúde bucal desenvolvidos em âmbito nacional, especialmente no Estado de 
São Paulo, tendo como referência o período de 1992 a 2001. O tema "programação em saúde bucal" foi levantado em bases de dados e bibliotecas da área da saúde. Dedalus (Banco de dados bibliográficos da USP); Bireme (Biblioteca virtual da saúde); LILACS (Literatura Latino-Americana e do Caribe em Ciências da Saúde) e BBO (Bibliografia Brasileira de Odontologia).

O material levantado (23 referências na base Dedalus, 13 na BBO e 11 na LILACS) e selecionado para o trabalho foi organizado de modo a permitir identificar categorias de atuação programática na área da saúde bucal.

\section{Resultados}

Embora nem todos os programas estudados possam ser considerados efetivamente programas em saúde bucal pelo caráter pontual, a revisão bibliográfica sobre o tema permitiu identificar quatro tendências: ações curativas e preventivas com práticas educativas; ações preventivas com bochechos fluorados e práticas educativas pontuais; práticas educativas com foco na informação e no uso de recursos mobilizadores; prevenção e práticas educativas de conscientização.

\section{Programas voltados ao tratamento curativo, prevenção e educação}

A literatura sobre o tema mostra muitos estudos descrevendo programas educativos e preventivos associados a tratamentos curativos (Sawazaki e Nakama, 1997; Takahashi e Ursi, 1997). Gonçalves e Silva (1992) elaboraram um plano de ação educativo no Centro Educacional de Palhoça, em Santa Catarina (regime de internato, semi-internato e externato), abordando aspectos educativos, preventivos e curativos, porque não havia no local nenhuma atividade direcionada à promoção de saúde bucal. O tratamento curativo foi realizado priorizando as necessidades epidemiológicas: inicialmente os primeiros molares permanentes, seguidos dos pré-molares, molares decíduos e incisivos e caninos permanentes. Paralelamente a esse atendimento, foram realizadas atividades preventivas como: escovação supervisionada, bochechos com solução fluorada e evidenciação de placa bacteriana. A abordagem do programa de saúde bucal esteve ancorada no tra- balho coletivo e na participação ativa dos diferentes sujeitos envolvidos no trabalho preventivo (equipe escolar e equipe de saúde), buscando construir uma rede de parcerias e integrar o tema "saúde bucal" na grade curricular da escola para viabilizar a continuidade do trabalho educativo e a consolidação do programa - uma das condições necessárias para garantir o impacto do trabalho coletivo. Concluíram que é possível a realização de programas educativos eficazes na escola, desde que toda a escola esteja envolvida e motivada.

\section{Programas voltados à prevenção com flúor e práticas educativas pontuais}

Para trabalhar com a prevenção da cárie dentária e da inflamação gengival, Milori et al. (1994) avaliaram 90 crianças de 7 a 9 anos de idade, de ambos os sexos, do ensino fundamental. Realizaram exames clínicos aplicando os critérios dos índices de gengivite (IG) e de placa bacteriana (IPL), apenas nos dentes permanentes. As crianças foram divididas aleatoriamente em três grupos distintos, recebendo diferentes tratamentos. No grupo 1, as crianças receberam tratamento educativo e preventivo (aula de educação sanitária sobre placa dentária bacteriana e inflamação gengival, aplicação tópica de flúor gel e escovação dentária supervisionada a cada 15 dias); no grupo 2, receberam apenas educação sanitária, apoiada em palestras pontuais, orientações fundamentadas em normas de conduta; e no grupo 3, apenas tratamento preventivo (aplicação tópica de flúor gel e escovação supervisionada a cada 15 dias). Comparando os resultados dos índices de gengivite e placa bacteriana obtidos após oito meses, os escolares do grupo 1, seguidos dos do grupo 3, foram os mais beneficiados pelos programas propostos.

Os resultados apresentados por Milori et al. (1994) confirmam a ineficácia das palestras e orientações pontuais. Embora apontem as práticas de prevenção apoiadas na aplicação de flúor associadas ao controle mecânico da placa dentária como ações de maior impacto, as práticas educativas desenvolvidas nesse programa, apoiadas na simples transmissão de informações com base na abordagem higienista (ancorada no paradigma comportamentalista), não expressam qualquer preocupação com a problematização da saúde bucal para o grupo populacional enfocado nem com a busca de estra- 
tégias capazes de viabilizar a continuidade de ações educativas entre os escolares.

Outro programa que pode ser destacado nesta tendência é o de Queluz (1995), desenvolvido na cidade de Piracicaba em escolas da rede pública. Incluiu 320 escolares de 6 a 15 anos de ambos os sexos. Todos os alunos foram submetidos a um questionário de 11 perguntas para levantar o nível de conhecimento sobre saúde bucal. Após a aplicação e avaliação do instrumento, desenvolveram o programa em saúde bucal mediante trabalho educativo pontual (palestras) e práticas de prevenção da cárie, por meio de higiene bucal e flúor. Os resultados analisados estatisticamente revelaram que $85 \%$ dos escolares participantes do estudo tinham menos de 11 anos de idade e apresentavam conhecimentos insuficientes sobre saúde bucal; $43 \%$ não tinham conhecimentos sobre o flúor na prevenção da cárie. Embora o autor não discuta o impacto do trabalho preventivo no grupo estudado, também aponta para as limitações de programas educativos ancorados em palestras e orientações pontuais em relação ao impacto na prevenção das doenças e na promoção da saúde bucal.

As práticas de prevenção com utilização de flúor, associadas ou não a práticas educativas pontuais têm sido muito utilizadas. Em Bauru, um levantamento epidemiológico de cárie dentária, realizado em 2001 por alunos da especialização do curso de odontologia em saúde coletiva, da Associação Paulista de Cirurgiões-Dentistas de Bauru, mostrou que a cidade obteve o menor índice de cárie dentária desde 1975, quando começou a fluoração da água na cidade. No início dessa implantação, o índice CPOD era de 9,89 e, em 1990, teve uma queda significativa para 3,9. Mas, o estudo mostrou também que, apesar da fluoração no ano de 1995, o índice CPO-D havia aumentado para 4,13, surpreendendo a todos e gerando novos desafios em relação à prevenção em saúde bucal.

A preocupação gerada com o aumento desse índice resultou no programa Sorria Bauru, iniciado em 1999 e desenvolvido em sistema de parceria entre Secretaria Municipal de Saúde (SMS), Universidade do Sagrado Coração, Universidade de São Paulo e Universidade Paulista (Agenda USP, 2002).

Atuando na Educação e Promoção de Saúde de crianças pertencentes às Escolas Municipais de Educação Infantil (EMEIs) da cidade de Bauru, o programa Sorria Bauru da SMS de Bauru visa diminuir o índice da doença cárie pelo desenvolvimento de métodos preventivos individuais e coletivos associados a práticas educativas: palestras mensais, escovação supervisionada, bochecho fluorado semanal e avaliação mensal sobre o conteúdo das palestras por meio de atividades escritas ou práticas (Programa Sorria Bauru, 1999).

Embora apoiado em palestras de caráter mais informativo, sem avançar no sentido de buscar uma problematização do tema para a população focada, a periodicidade das atividades garantiu alcançar um índice de 1,44, no final de 2001, mostrando impacto no trabalho preventivo pela associação da prática dos bochechos com flúor e o trabalho educativo mais sistemático.

Pinto (2000) ressalta que a fluoração das águas de abastecimento e dos dentifrícios são medidas que podem permitir a universalização do uso do flúor no país e contribuir decisivamente para o declínio e controle da cárie dentária na população. Mas, para garantir o seu uso seguro, os sanitaristas concordam com Manfredini (1996) que, além de medidas de heterocontrole, preconiza que sejam adotadas medidas para impedir a comercialização de medicamentos e produtos de uso sistêmico que contenham flúor em sua composição, considerando que o excesso de flúor pode levar à fluorose dentária, que se caracteriza clinicamente pelo aparecimento de estrias esbranquiçadas, em geral horizontais e translúcidas, no esmalte no período de calcificação dos dentes (Pinto, 2000).

\section{Programas voltados a práticas educativas com foco na informação e no uso de recursos mobilizadores}

Garcia et al. (1998) desenvolveram programa de prevenção e educação em saúde bucal utilizando material audiovisual, orientação direta e apresentação do Robô-Dente. Avaliaram o aprendizado de 682 crianças das primeiras às quartas séries do ensino fundamental de três escolas públicas da cidade de Araraquara, submetidas a esse programa educativo em saúde bucal, mediante análise de redações feitas pelas crianças, após 15 dias da aplicação do programa, utilizando palavras-chave no contexto da saúde bucal. A programação, apoiada na avaliação neurolingüística das informações, valorizou o trabalho com os sentidos: visual, auditivo e cinestésico. Esteve apoiada em três modelos de práticas informativas: palestras, para 
estimular os sentidos visual e auditivo; atividade clínica de educação e higiene bucal, cujo principal estímulo foi o cinestésico e tátil-motor, além do estímulo auditivo e visual; e utilização de recurso (o Robô-Dente) para trabalhar informação, que foi centralizada no estímulo auditivo e visual, que, embora colabore no processo de retenção de informações, não garante a consciência da necessidade do cuidado com a saúde. Os autores do estudo constataram que apesar de a proposta ter tido grande aceitação, programas baseados no binômio prevenção-educação precisam ser realizados com continuidade para que ganhem impacto.

Dinelli et al. (1998) desenvolveram programa educativo em saúde bucal, com 90 alunos do ensino fundamental da rede particular da cidade de Araraquara, apoiado na informação e uso de recurso didático-pedagógico: o RobôSorriso que transmitia, por gravação em fita cassete, mensagens educativas às crianças. Pelo estudo, concluíram que houve motivação, assimilação e retenção do conhecimento. Ressaltaram que o bom nível das respostas obtidas nas avaliações realizadas deveu-se, principalmente, às condições socioeconômico-culturais do grupo de estudantes, que pertencia à rede particular de ensino.

Embora mostrando dados de impacto relativos ao aprendizado dos escolares com o programa, a abordagem utilizada para trabalhar as informações e avaliar esse impacto está nitidamente ancorada em métodos preventivos mais tradicionais, apoiados em concepções de ensino-aprendizagem pautadas pela memorização de informações, o que se sabe hoje não ser suficiente para transformar o conhecimento em algo significativo, capaz de concretizar-se em práticas emancipatórias, geradoras de autonomia em relação aos próprios cuidados com a saúde (Ayres, 2002).

\section{Programas voltados à prevenção e práticas educativas de conscientização}

Gomes et al. (1993) observaram a necessidade de utilizar práticas educativas conscientizadoras. Participaram do projeto 40 crianças entre 8 e 10 anos. O processo incluiu o exame clínico para avaliar a condição de saúde bucal das crianças e práticas educativas de mobilização e conscientização. Observaram que no início do trabalho $60 \%$ dos dentes examinados apresentavam placa bacteriana visível a olho nu. No decorrer do processo, essa placa, que era visível e potencialmente patológica, decaiu para $12 \%$ após a intervenção das instrutoras. Também chamou atenção a existência de manchas brancas em $47 \%$ das superfícies examinadas. No decorrer do trabalho as manchas brancas ativas diminuíram $7,4 \%$ e esse nível foi mantido até o final do processo (quatro meses). Houve um aumento das superfícies hígidas, devido ao uso do flúor e controle de placa, sendo este mantido durante os quatro meses. Os autores concluem que, pela conscientização sobre a importância da saúde bucal na vida das pessoas, a educação em relação aos métodos preventivos e a ênfase na motivação por meio de recursos materiais e humanos, houve praticamente uma reversão do quadro inicial.

\section{Críticas ao recorte dos programas estudados}

Pinto (2000) ressalta que a educação em saúde bucal (ESB) é uma ação importante do processo de promoção da saúde, exigindo características específicas que envolvem práticas e conhecimento. Contudo, ressalta que o conceito de educação em saúde bucal precisa ser ampliado para incluir, entre suas tarefas, o trabalho de conscientização com os grupos sociais com menor acesso aos programas de saúde odontológica. Invocando as propostas do educador Paulo Freire (1980), o autor traz o termo conscientização como estratégia que leva a uma aproximação crítica da realidade, valorizando o conhecimento como possibilidade de autonomia para que cada sujeito possa criar sua existência com o material que a vida lhe oferece.

Falar de prática educativa em saúde bucal não é suficiente nem garante a qualidade do trabalho de promoção da saúde e prevenção das doenças. A educação, muitas vezes, chega de modo abstrato, descolada da realidade da população. Como relata Freire (apud Pinto, 2000), é muito difícil aprender e reter conhecimentos quando a preocupação maior é a sobrevivência e os educadores falam de coisas como Eva $e$ as uvas, existindo homens que sabem muito pouco de Eva e nunca comeram uvas.

Ainda que muitos programas venham aparecendo nos últimos anos, a educação em saúde bucal ainda é um desafio: nem sempre consegue ganhar sentido entre os grupos sociais desenvolvidos. A presença de programas sem a 
preocupação com a continuidade das propostas e, na maioria das vezes, priorizando os tratamentos preventivos medicalizadores e curativos em detrimento da educação, ainda torna as práticas educativas um desafio no campo da saúde pública na área de odontologia, principalmente quando se analisa a prevalência mundial das odontopatias, aliada ao alto custo do tratamento restaurador e à compreensão que hoje temos de que o tratamento sintomático das doenças não é suficiente para garantir a saúde bucal, como afirmam Yatsuda e Ramos (1998).

Embora os próprios estudos analisados situem a prática educativa como componente importante e necessário à redução dos problemas de saúde bucal, o conceito de educação em saúde na área de odontologia ainda não ganhou espaço de discussão. Poucos programas mostram estratégias de ruptura com propostas mais tradicionais e comportamentalistas, ancoradas em práticas comunicacionais unidirecionais que não possibilitam o diálogo nem a participação efetiva dos alunos, necessários à construção de um conhecimento emancipatório que produza autonomia em relação aos cuidados com a saúde bucal. A exemplo da observação de Pinto (2000) sobre a necessidade de incorporar uma dimensão conscientizadora no trabalho de educação em saúde, na educação de escolares, talvez o primeiro desafio seja incorporar uma dimensão problematizadora nas práticas educativas, apoiada nos estudos de Freire (2000), abrindo espaço para uma prática participativa em que os alunos possam ser protagonistas do processo de ensino-aprendizagem.

\section{A educação em saúde odontológica: a comunicação como desafio}

Ao lado da análise desses programas, é necessário reconhecer também o despreparo dos profissionais da odontologia quanto às práticas de comunicação e informação utilizadas para desenvolver hábitos adequados de manutenção da saúde bucal. No estudo de Moimaz et al. (1994), os autores avaliaram a utilização dos métodos de prevenção e educação em saúde bucal por cirurgiões-dentistas dos serviços público e particular. A análise desse estudo, realizado a partir de questionários aplicados aos profissionais, permitiu concluir que, apesar da utilização de medidas preventivas por grande parte dos profissionais entrevistados, na prática de atendimento ao paciente, a educação odontológica não estava sendo realizada de maneira sistemática em ambos os serviços avaliados. Apesar de grande parte deles ter respondido orientar os pacientes, os autores verificaram que aproximadamente a metade dos profissionais do serviço público e particular destinava apenas uma breve sessão para este fim, com duração máxima entre 20 e 25 minutos, tempo considerado insuficiente para uma comunicação efetiva, com possibilidades de aprendizagem e construção de conhecimentos novos. Esta verificação reafirma a necessidade das práticas de educação e prevenção em saúde bucal.

Bijella (1993) também observou que a prática do cirurgião-dentista não deve se voltar apenas à dimensão técnica, curativa; precisa incorporar uma dimensão de educação em saúde bucal, fornecendo informações, orientações e desenvolvendo habilidades de cuidado por meio de métodos que mobilizem o cuidado com a saúde bucal, buscando no paciente um colaborador e não apenas o alvo do programa de prevenção. A autora enfatiza ainda que a educação em saúde bucal significa aquisição de conhecimentos, desenvolvimento de habilidades, atitudes e construção de valores que levem o paciente e/ou seus pais a agirem, no seu dia-a-dia, em benefício da própria saúde bucal e da saúde dos outros. Ressalta que a educação em saúde, realizada no ambiente escolar, pode favorecer o envolvimento da criança para trabalhar e construir novos conhecimentos, facilitando a mudança de atitudes, hábitos e cuidados, na faixa etária pré-escolar e escolar. E este é um desafio que não é exclusivo do cirurgião-dentista.

Para Pinto (2000), há uma tendência a acreditar que as pessoas cujas necessidades básicas são satisfeitas motivam-se mais facilmente e consomem ensinamentos educativos até mesmo de modo voluntário. Relata, no entanto, que nas décadas de 1960 e 1970, diante dos resultados positivos obtidos em projetos piloto em comunidades carentes, muitos pesquisadores chegaram a acreditar que bastaria a educação para que as populações carentes modificassem seus hábitos. Mesmo que, nos dias atuais já tenhamos clareza das possibilidades e limites da educação diante dos condicionantes sociais e econômicos, muitos cirurgiões-dentistas ainda têm visão mais ou menos ingênua, responsabilizando as próprias pessoas por todos os problemas de saúde que apresentam.

Com essa visão ingênua e pouco crítica dos condicionantes sociais e econômicos que inter- 
ferem na saúde da população, parte dos cirurgiões-dentistas não percebe a complexidade dos determinantes que levam à extração e às próteses como única alternativa para as populações mais pobres. Como observa Pinto (2000), é certo que programas educativos apoiados nessa visão pouco crítica estão fadados a falhar, pois desconsidera a desnutrição, o custo dos alimentos, o difícil acesso aos serviços de saúde em geral, além do fato de os centros de saúde praticarem a odontologia curativa apoiada em extrações radicais. Sem acesso aos serviços e enfrentando tantas carências, grande parte da população não consegue valorizar os problemas dentários e dos tecidos moles da boca.

O ensino de saúde tem sido um desafio para a educação, no que se refere à possibilidade de garantir uma aprendizagem efetiva e transformadora de atitudes e hábitos de vida. As experiências mostram que transmitir informações a respeito do funcionamento do corpo e descrição das características das doenças, bem como um elenco de hábitos de higiene, não é suficiente para que os alunos desenvolvam atitudes de vida saudável. É preciso educar para a saúde levando em conta todos os aspectos envolvidos na formação de hábitos e atitudes que acontecem no diaa-dia escolar (Brasil, 1997).

Embora a educação, sozinha, não tenha forças para possibilitar a saúde desejável à população, pode fornecer elementos que capacitem os indivíduos para ganhar autonomia e conhecimento na escolha de condições mais saudáveis. A Educação para a Saúde como fator de promoção e proteção à saúde é, também, uma estratégia para a conquista dos direitos de cidadania (Brasil, 1997).

\section{Considerações finais}

Com este estudo procuramos identificar algumas tendências encontradas nos programas odontológicos, ressaltando suas principais características. Observamos que, apesar da existência de vários programas, a dimensão educativa é pouco desenvolvida e, quando realizada, está fortemente apoiada em práticas de transmissão de conhecimentos, sem espaço para práticas dialógicas capazes de mobilizar as crianças quanto à problemática da saúde bucal, visando a autonomia em relação ao cuidado com a saúde.

Como observa Ayres (2002), em estudo crítico sobre as práticas educativas no âmbito das doenças sexualmente transmissíveis, especialmente do HIV/Aids, as estratégias educativas em saúde ainda não passam da superfície do problema, observando que, mais uma vez, precisamos recorrer às teorias de Paulo Freire para avançar no trabalho educativo, abrindo espaço para a discussão dos temas de saúde e não apenas transmitir informação. É preciso ultrapassar o paradigma comportamentalista, ancorado na abordagem higienista e individualista da prevenção para construir métodos mais dialógicos e construtivistas, que substituam a atitude normativa e modeladora de comportamento pela atitude emancipatória, valorizando a interação entre pares, a reflexão, o protagonismo dos alunos e a busca de parcerias (escola, universidade, serviços de saúde, ONGs) para viabilizar a continuidade dos programas implantados.

É preciso substituir modelos ancorados em práticas de comunicação unidirecional, dogmática e autoritária com foco na transmissão de informação, pela discussão e reflexão, desencadeadas pela problematização de temas de saúde bucal.

\section{Referências bibliográficas}

Agenda USP de Notícias 2002. Cai índice de cárie dentária em Bauru. Brasil. Informativo 8/4/2002. Disponível em <www.usp.br/agen/bols/2002/rede937.htm>. Acesso em 24 de outubro de 2002.

Ayres JRCM 2002. Práticas educativas e prevenção de HIV/Aids: lições aprendidas e desafios atuais. Interface - Comunicação Saúde, Educação 6(11):11-24.

Ayres JRCM 2001. Sujeito, intersubjetividade e práticas de saúde. Ciência \& Saúde Coletiva 6(1):63-72.

Barros AJD \& Bertoldi AD 2002. Desigualdades na utilização e no acesso a serviços odontológicos: uma ava- 
liação em nível nacional. Ciência \& Saúde Coletiva 7(4):709-717.

Bastos RS et al. 2002. Declínio da cárie dentária e incremento no percentual de escolares, de 12 anos de idade, livres da doença em Bauru, São Paulo, entre 1976 e 1995. Revista da Faculdade de Odontologia de Bau$r u$ 10(2):75-80.

Bijella MFTB 1993. A importância da educação odontológica em saúde bucal nos programas preventivos para a criança. Cecade News 1(1/2):25-28.

Botazzo C 1994. A saúde bucal nas práticas coletivas de saúde. Instituto de Saúde (Série Tendências e Perspectivas em Saúde 1)

Brasil 1988. Ministério da Saúde. Secretaria Nacional de Programas Especiais de Saúde. Divisão Nacional de Saúde Bucal. Fundação de Serviços de Saúde Pública. Levantamento epidemiológico em saúde bucal. Brasil, Zona Urbana, 1986. Centro de Documentação do Ministério da Saúde, Brasília.

Brasil 1989. Política Nacional de Saúde Bucal. Divisão Nacional de Saúde Bucal. Disponível em http:// drt2001.saude.gov.br/sps/areastecnicas/bucal/publicacoes/. Acesso em 24 de outubro de 2002.

Brasil 1993. Ministério da Saúde. Secretaria Nacional de Programas Especiais de Saúde. II Conferência Nacional de Saúde Bucal. Relatório Final 1993. Disponível em http://drt2001.saude.gov.br/sps/areastecnicas/ bucal/publicacoes/publicacoes.htm. Acesso em 24 de outubro de 2002.

Brasil 1997. Parâmetros curriculares nacionais: meio ambiente, saúde (9). Secretaria de Educação Fundamental, Brasília.

Brasil 1999. Ministério da Saúde. Secretaria Nacional de Programas Especiais de Saúde. Divisão Nacional de Saúde Bucal. Fundação de Serviços de Saúde Pública. Levantamento epidemiológico em saúde bucal. Brasil, Zona Urbana, 1998. Centro de Documentação do Ministério da Saúde, Brasília.

Collares CA, Moyses MA \& Lima GZ. 1985. Saúde escolar e merenda : desvios do pedagógico? Educação e Sociedade (20):10-20.

Cyrino EG 1994. Estudo de um programa de saúde do escolar em uma escola estadual da periferia de Botucatu. Dissertação de mestrado. Universidade de São Paulo, Faculdade de Medicina de São Paulo.

Dinelli W, Corona SAM, Garcia PPNS \& Dinelli TCS 1998. Campanhas de prevenção e motivação em odontologia: Novos caminhos. Odonto 2000 2(1):8-13.

Frazão P 1998. Ciências sociais e saúde bucal, pp. 166 167. In C Botazzo \& SFT Freitas (org.). Tecnologias em saúde bucal coletiva. EDUSC-Editora UNESP, Bauru-São Paulo.

Freire P 1980. Conscientização: teoria e prática da libertação, uma introdução ao pensamento de PF. Morais, São Paulo.

Freire P 2000. Pedagogia da autonomia: saberes necessários à prática educativa. (15 ed.). Paz e Terra, São Paulo.

Garcia PPNS, Corona SAM \& Valsecki Júnior 1998. A educação e motivação: segunda avaliação da efetividade de métodos educativos-preventivos relativos à cárie dental e à doença periodontal. Revista de Odontologia da Unesp 27(2):405-415.

Garrafa V 1993. Saúde bucal e cidadania. Saúde em Debate 41:50-57.

Gomes AS, Gianlup EM \& Abreu CB 1993. A importância da conscientização e da prática preventiva em odontologia. Revista Odontologia e Ciência 8(16): 115-125.

Gonçalves RMG \& Silva RHH 1992. Experiência de um programa educativo-preventivo. $R G O$ 40(2):97-100.

Manfredini MA 1996. Quando o flúor pode se tornar um malefício. Revista da Associação Paulista dos Cirurgiões Dentistas 50(1):15-16.

Milori AS, Nordi PP, Vertuan V \& Carvalho J 1994. Respostas de um programa preventivo de placa dentária bacteriana. Revista de Odontologia da Unesp 23(2): 325-231.

Moimaz SAS, Saliba NA, Saliba O \& Almeida JCF 1994. Educação para saúde bucal e prevenção. Avaliação entre cirurgiões-dentistas de serviço público e particular. $R G O$ 42(2):71-74.

Narvai PC 1994. Odontologia e saúde bucal coletiva. Hucitec, São Paulo.

Nemes MIB 1996. Saúde do adulto, pp. 48-63. In IB Schraiber, MIB Nemes \& RBM Gonçalves (org.). Programas e ações na unidade básica. Hucitec, São Paulo.

OPAS/OMS 2001. Organização Pan-Americana da Saúde/Organização Mundial da Saúde. Informativo 4/5/2001. Disponível em <www.opas.org.br/siste mas/fotos/bucal.htm $>$. Acesso em 17 de outubro de 2002.

Pinto VG 1992. A questão epidemiológica e a capacidade de resposta dos serviços de saúde bucal no Brasil. Tese de doutorado. Universidade de São Paulo, Faculdade de Saúde Pública.

Pinto VG 2000. Saúde bucal coletiva. (4 ed.). Santos, São Paulo.

Porto VMC 2002. Saúde bucal e condições de vida: uma contribuição do estudo epidemiológico para a inserção de atenção à saúde bucal no SUS. Dissertação de mestrado. Universidade Estadual Paulista Júlio de Mesquita Filho, Faculdade de Medicina de Botucatu.

Programa Sorria Bauru 1999. Secretaria Municipal de Saúde. (Mimeo).

Queluz DP 1995. Cárie e conhecimento do flúor "na prevenção de escolares". RGO 43(3):167-170.

Sawazaki I \& Nakama L 1997. Educação para a SB: trabalho em equipe e aspectos psicossociais. Semina 18(espec.):15-24.

Silveira Filho ADA 2002. A saúde bucal no PSF: o desafio de mudar a prática. Brasil, Programa Saúde da Família.

Soares EL 1988. Educação em saúde bucal nas escolas estaduais do 1 g grau do município de São Paulo. Tese de doutorado. Universidade de São Paulo, Faculdade de Saúde Pública, São Paulo.

Takahashi C \& Ursi WJS 1997. Avaliação da influência do Programa Educativo-Preventivo Odontológico da UBS do Jardim Alvorada (Londrina-PR/Brasil) sobre a educação dos pais das crianças usuárias. Semina 18(espec.):90-97.

Thylstrup A \& Fejerskov O 1995. Cariologia clínica. Santos, São Paulo.

Yatsuda RA \& Ramos DLP 1998. O papel do educador em saúde bucal na pré-escola. O Mundo da Saúde 22(1): 15-22.

Artigo apresentado em 5/8/2003

Aprovado em 10/10/2003

Versão final apresentada em 25/10/2003 